\title{
Ueber die Bildung des Leucinimids bei der peptischen und tryptischen Verdauung des Oxyhämoglobins resp. des Globins. Von
}

S. Salaskin.

(Aus dem chemischen Laboratorium des Instituts für experimentelle Medicin in St. Petersburg.)

(Der Redaction zugegangen am 29. Mai 1901.)

Anlässlich meiner noch nicht abgeschlossenen Untersuchungen über die Spaltungsprodukte des Hämoglobins resp. des Globins bei der peptischen und tryptischen Verdauung habe ich eine bis jetzt als Produkt der Eiweissverdauung unbekannte krystallinische Substanz aufgefunden, die sich bei näherer Untersuchung als Leucinimid herausstellte.

Das Verfahren, wobei ich das Leucinimid aufgefunden habe, war folgendes: krystallinisches Oxyhämoglobin, das auf die übliche Weise aus den Blutkörperchen des Pferdeblutes erhalten war, wurde bei $38^{\circ}$ C. mit Magensaft, der von Hunden nach der Pawlow'schen Methode erhalten war, verdaut. Die angewandte Menge des Magensaftes war dem Gewichte nach 10-20 Mal grösser als die des 0xyhämoglobins. Der Magensaft wurde nicht auf einmal, sondern in kleinen Portionen in Zwischenräumen von 3-5 Tagen hinzugefügt. Die Verdauungsdauer schwankte $z$ wischen 8-30 Tagen, dabei wurde gewöhnlich nach 2-3 Tagen die Verdauungsmischung von dem gefällten Hämatin abfiltrirt und das gelbgefärbte Filtrat der weiteren Verdauung unterworfen. Um die Fäulniss zu verhüten, setzte ich der Flüssigkeit etwas Chloroform und Aether hinzu.

Nach beendeter Verdauung wurde die Flüssigkeit mit Soda neutralisirt, mit Essigsäure schwach angesäuert und auf 
dem Wasserbade bis zur Syrupconsistenz eingedampft. Die syrupöse Lösung wurde nach dem Erkalten von dem, meistens in geringer Menge entstandenen, Niederschlage abfiltrirt und das Filtrat mit dem mehrfachen Volumen Alkohol übergossen. Nach 24 Stunden ist ein klebriger, an den Wänden des Glases fest haftender Niederschlag entstanden, von welchem die klare Flüssigkeit leicht abgegossen werden konnte. Die filtrirte, gelbliche alkoholische Lösung wurde auf dem Wasserbade von Neuem bis zur Syrupconsistenz eingedampft und wiederum mit dem 5-6 fachen Volumen Alkohol übergossen, der dabei entstandene Niederschlag wurde abfiltrirt und das Filtrat jetzt zur Trockne eingedampft. Der trockne Rückstand wurde wiederholt mit absolutem Alkohol ausgekocht, die abfiltrirte; heisse, alkoholische Lösung stehen gelassen, wobei sich nach dem Erkalten ein Niederschlag bildete, der abfiltrirt und das Filtrat auf dem Wasserbade bis zur Syrupconsistenz eingedampft wurde. Aus dem jetzt erhaltenen Syrup können die Krystalle des Leucinimids nach den zwei folgenden Methoden isolirt werden:

1. $\mathrm{Zu}$ dem noch heissen Syrup wird Wasser hinzugefügt, wobei sogleich ein krystallinischer, öfters aber nur amorpher Niederschlag entsteht. Wird er indessen mit Wasser gekocht, so ist der beim Erkalten entstandene Niederschlag stets krystallinisch. Die Ausbeute an Krystallen ist aber gering, da ein erheblicher Theil der Substanz in der Lösung bleibt.

2. Der Syrup wird wiederholt mit Essigäther extrahirt. Die ätherischen Auszüge zur Trockne verdunstet, der Rückstand in heissem Wasser gelöst und bis zur beginnenden Krystallisation eingedampft oder der Rückstand wird in wenig heissem Alkohol gelöst, zu der filtrirten und auf dem Wasserbade eingeengten Lösung etwa das doppelte Volumen Wasser hinzugefügt, worauf das Leucinimid krystallinisch ausfällt.

Bei der Verdauung mit dem nach Pawlow erhaltenen pankreatischen Safte wurde das Hämatin erst nach beendeter Verdauung entfernt, weil dank der alkalischen Reaction, das Hämatin sich auflöste und erst nach dem Ansäuern mit Essigsäure ausfiel. Die davon abfiltrirte Flüssigkeit wurde ein- 
gedampft und dann mit Alkohol gefällt, der verdunstete alkoholische Auszug wurde mit Alkoholäther extrahirt, das Filtrat verdunstet und der Rückstand mit Essigäther extrahirt. Die ätherischen Auszüge wurden zur Trockne eingedampft. Nach Verdunsten des Essigäthers wurde der trockne Rückstand mit kaltem, absolutem Alkohol zerrieben, wobei das Leucinimid krystallinisch hinterblieb. Die Krystalle wurden aus heissem Alkohol umkrystallisirt und scheiden sich daraus beim Erkalten in atlasglänzenden Nadeln aus. Zweckmässig ist auch hier, die heisse alkoholische Lösung einzuengen und das Leucinimid durch Wasserzusatz auszufällen.

Bezüglich der Ausbeute und vortheilhaftesten Zeitdauer kann ich sowohl hinsichtlich der peptischen wie der tryptischen Verdauung keine bestimmten Angaben machen, zumal die Isolirung und Reindarstellung des Leucinimids mit grossen Verlusten verbunden ist. In einem Falle habe ich bei der Pepsinverdauung nach 30 tägiger Dauer $0,3 \%$ vom Gewicht des angewandten Oxyhämoglobins erhalten. Die Isolirung des Leucinimids bei der Trypsinwirkung ist noch viel schwieriger; aus $100 \mathrm{~g}$ des Oxyhämoglobins habe ich nach 5tägiger Verdauung ca. $0,1 \mathrm{~g}$ des Leucinimids erhalten.

Die reinen Krystalle sind in Wasser bei Zimmertemperatur: fast unlöslich, viel leichter in heissem, wenig löslich in Aether, viel leichter in Essigäther; am besten in siedendem $96 \%$ igen Alkohol, etwas weniger in absolutem. Die Löslichkeit der nicht völlig reinen Krystalle ist in allen oben erwähnten Lösungsmitteln eine viel grössere. Bemerken will ich, dasss die bei der peptischen Verdauung erhaltenen Krystalle leichter löslich als die bei der tryptischen sind. In Säuren undl Alkalien sind die Krystalle nicht mehr als wie in reinem Wasser löslich. Trocken erhitzt, sublimiren sie leicht unter Bildung voluminöser, aus verfilzten weissen Nadeln bestehendem Flocken.

Die Krystalle, die bei der tryptischen Verdauung gewonnen wurden, schmelzen nach dem Trocknen bei $295-296^{\circ} \mathrm{C}$. Der Schmelzpunkt bleibt derselbe für verschiedene Fractionen, auch nach mehrfachem Umkrystallisiren aus heissem Alkoholl. 
Dagegen ist es mir nicht gelungen, bei der peptischen Verdauung ein Produkt von constantem Schmelzpunkt zu erhalten. Die erste Fraction der Krystalle, die durch Wasserzusatz zu der heissen concentrirten alkoholischen Lösung gewonnen wurde, schmolz bei $250^{\circ} \mathrm{C}$. Diese Krystalle sind in kaltem, absolutem Alkohol leicht löslich und werden daraus durch Aether nicht gefällt. Eine zweite Fraction, die durch Zusatz von etwas Wasser zu dem alkoholischen Filtrate erhalten wurde, schmolz bei $267^{\circ}$ C. Diese Krystalle sind in absolutem Alkohol in der Siedehitze nur wenig löslich, und beim Erkalten bildete sich nur ein minimaler Bodensatz. Durch Aether werden sie aus der alkoholischen Lösung gefällt. Der Schmelzpunkt der mit Aether gefällten und im Vacuo getrockneten Krystalle lag bei $273-274^{\circ} \mathrm{C}$. Die Krystalle der bis zur Trockne eingedampften Mutterlauge schmolzen bei $253^{\circ} \mathrm{C}$.

Die Elementaranalyse der bei der peptischen Verdauung und an der Luft bis zu constantem Gewichte getrockneten Krystalle (bei $105^{\circ}$ C. verloren sie nichts an Gewicht) gab folgende Resultate:

$$
\begin{aligned}
& 0,1990 \text { g Substanz: } 0,4650 \mathrm{CO}_{2}, 0,1680 \mathrm{H}_{2} \mathrm{O} \text {, } \\
& 0,2102 \text { > } 22,6 \mathrm{ccm} . \mathrm{N}\left(18^{\circ} \text { C. und } 755,2 \mathrm{~mm}\right. \text {.). } \\
& \text { Für } \mathrm{C}_{8} \mathrm{H}_{11} \mathrm{NO} \text { berechnet: C. 63,83, H 9,73, N 12,39. } \\
& \text { Gefunden: , 63,72, > 9,38, > 12,39. }
\end{aligned}
$$

Aus Mangel an Material konnte ich die Analyse der bei der tryptischen Verdauung gewonnenen Krystalle nicht ausführen. Das äussere Aussehen und die Eigenschaften dieser Krystalle waren dieselben wie die von der peptischen Verdauung; sie unterschieden sich von denselben nur durch die Löslichkeit und höheren Schmelzpunkt.

Um das bei der peptischen und pankreatischen Verdauung von mir erhaltene Produkt mit dem aus Leucin erhaltenen Leucinimid $\mathrm{zu}$ vergleichen, habe ich das letztere nach der Vorschrift von E. Fischer ${ }^{1}$ ) dargestellt. Der Schmelzpunkt des so gewonnenen Präparates lag bei $269-270^{\circ} \mathrm{C}$. und in allen übrigen Eigenschaften war das bei der peptischen

1) Ber. d. dtsch. chem. Ges. 36, $448,1901$. 
Verdauung erhaltene Leucinimid mit dem aus Leucin erhaltenen identisch.

Leucinimid als Spaltungsprodukt bei der hydrolytischen Zersetzung der Eiweissstoffe ist schon durch die Untersuchungen früherer Forscher als sogenannte Bopp'sche Substanz bekannt. In jüngster Zeit (1897) beschrieb Cohn ${ }^{1}$ ) einen von ihm als Pyridinderivat von der Zusammensetzung $\mathrm{C}_{5} \mathrm{H}_{7} \mathrm{NO}$ aufgefassten Körper, den er bei der Spaltung des Caseins mit kochender Salzsäure isolirt hatte. Kurz darauf machte Ritthausen ${ }^{2}$ ) auf die grosse Aehnlichkeit dieses Pyridinderivates mit dem Leucinimide aufmerksam. $\mathrm{Cohn}^{3}$ ) verglich darauf sein Pyridinderivat mit dem von Ritthausen bei der hydrolytischen Spaltung der Eiweissstoffe erhaltenen, sowie mit dem aus Leucin synthetisch dargestellten Leucinimid und kam zu der Ueberzeugung, dass alle diese Körper als identisch resp. isomer anzusehen seien, bemerkte aber, dass seine Substanz von den Krystallen des aus Leucin erhaltenen Leucinimids sich durch den um $33^{\circ}$ höheren Schmelzpunkt, leichtere Löslichkeit in Alkohol und leichtere Löslichkeit in Aether unterscheidet. ${ }^{4}$ ) Der Cohn'sche Körper schmolz bei $295-296^{\circ} \mathrm{C}$. ; das synthetisch dargestellte Leucinimid bei $262^{\circ}$ C. Ferner kam Cohn ${ }^{5}$ ), auf Grund seiner Untersuchungen zu dem Schlusse, dass das Leucinimid eine cyklische Verbindung, ein Dibutyldiacipiperazin<smiles>CC[C@@H]1N[C@@H](CC)NC1=O</smiles>

sei und dass die empirische Formel des Leucinimids $\mathrm{C}_{6} \mathrm{H}_{11} \mathrm{NO}$ ) verdoppelt werden muss.

E. Fischer ${ }^{6}$ ) fand den Schmelzpunkt für 3,6 Diisobutyl,

1) Zeitschr. f. physiol. Chem., Bd. XXII, S. 1553, 1897.

2) Ber. d. dtsch. chem. Ges., 29, 2109, 1897.

3) Zeitschr. f. physiol. Chem., Bd. XXIX, S. 283, 1900.

4) 1. c. 286 .

5) 1. c. 299 .

6) Ber. d. dtsch. chem. Ges., 34, 448, 450, 1901. 
2,5 Diacipiperazin $271^{\circ}$ C. (corr.), für 3,6 Dibutyl, 2,5 Diacipiperazin $268^{\circ}$ C. (corr.).

Das von mir bei der tryptischen Verdauung isolirte Leucinimid schmilzt bei $295-296^{\circ}$ C. und ist in jeder Hinsicht mit dem von Cohn erhaltenen Körper identisch. Das bei der tryptischen Verdauung erhaltene, sowie das Cohn'sche Leucinimid können daher mit den von E. Fischer untersuchten Leucinimiden nur isomer sein.

Was nun das bei der peptischen Verdauung entstandene Leucinimid betrifft, so ist es mir zwar nicht gelungen, ein Produkt von constantem Schmelzpunkt zu isoliren, doch näherte er sich in einigen Fractionen dem Schmelzpunkte des synthetischen Leucinimids. Vermuthlich hängt der niedrigere Schmelzpunkt dieses Leucinimids von einer geringen Beimischung eines isomeren ab, von welchem bei der geringen Menge des erhaltenen Materials ich die Hauptmenge durch offtere Krystallisation nicht befreien kounte.

Das Ergebniss meiner bisherigen Versuche zeigt, dass: 1. bei der protrahirten peptisehen Verdauung auch krystalloide Produkte entstehen, was schon von Hoppe-Seyler und vor Kurzem von Lawrow hervorgehoben wurde und 2., dass, je nachdem die Verdauung in peptischer oder tryptischer Lösung vor sich geht, isomere Leucinimide entstehen, die entgegen der Meinung von Cohn und Ritthausen nicht etwa weitere Umwandlungsprodukte des primär abgespaltenen Leucins, sondern aller Wahrscheinlichkeit nach schon im Globinmolekül präformirt sind. Weitere Versuche werden zeigen, ob auch aus anderen Eiweissstoffen bei der Magen- resp. Pankreasverdauung ebenfalls Leucinimide abgespalten werden. 